\section{DINÁMICA HABITACIONAL EN CHILLÁN, CHILE $(1906-2013)^{1}$}

Claudia Paola Espinoza Lizama²

\section{HOUSING DYNAMICS IN CHILLAN, CHILE (1906-2013) ${ }^{1}$}

Claudia Paola Espinoza Lizama²

\section{Resumen}

La dinámica habitacional en la ciudad de Chillán durante el periodo 1906-2013, se explica mediante factores políticos, económicos, históricos y físicos naturales que se manifiestan en la actual morfología de la ciudad.

La evolución histórica de la ciudad y las políticas habitacionales que se han implementado en el país, han tenido consecuencias en la actual distribución residencial de la ciudad. Es así que desde el año 1906, cuando el Estado de Chile genera las primeras soluciones a los problemas habitacionales, mediante la dictación de la Ley $\mathrm{N}^{\circ} 1.838$ de Habitaciones para Obreros, se interviene de manera

\section{Abstract}

The housing dynamics of Chillan during the 1906-2013 period can be explained through the political, economic, historical and physicalnatural factors that are currently present in the morphology of the city.

Both the historical evolution of the city and the housing policies implemented in the country have had an impact on the current residential distribution of Chillan. Connected to this is the first measure taken by the State of Chile to address the housing issue was the Act $n^{\circ} 1838$ of 1906 on Workingclass Housing, which meant the direct intervention 
directa en la distribución socio-espacial de los habitantes. Dicha Ley marca el nacimiento en Chillán de las primeras poblaciones obreras a principio del siglo XX, las que se vieron transformadas posteriormente por los desastres físicos naturales y los cambios de modelos económicos, que modificaron la morfología y marcaron el crecimiento de la ciudad. También influye en la actual distribución residencial el aumento demográfico sostenido que se ha registrado durante los últimos 100 años, y la posición y situación político administrativa que ha ocupado Chillán desde su fundación en el año 1580.

\section{PALABRAS CLAVE: DINÁMICA HABITACIONAL, CRECIMIENTO HORIZONTAL, FACTORES DE CRECIMIENTO.}

Fecha de recepción: 14.06.14

Fecha de aceptación: 29.08.14

1 Resultados del Proyecto de Investigación Regular DIUBB 124624 3/I, titulado “Dinámica habitacional en la ciudad de Chillán, periodo 1906-2010", financiado por la Universidad del Bío Bío, años 2012-2013.

2 Chile. Licenciada en Geografía, Pontificia Universidad Católica de Chile. Magíster en Educación, ULARE. Doctora (c) Ordenamiento Territorial y Desarrollo Sostenible, Universidad Nacional de Cuyo, Argentina. Académica jornada completa Escuela de Historia y Geografía, Departamento de Ciencias Sociales, Facultad de Educación y Humanidades, Universidad del Bío Bío. Correo electrónico: cespinoza@ubiobio.cl on the socio-spatial distribution of residents. This Act marked the birth of the first working-class neighborhoods in Chillan at the beginning of the 20th century. These were subsequently transformed by natural disasters and changes in economic models; these events modified the morphology of the city and triggered the growth of its metropolitan area. Likewise, the sustained population growth experienced by the city over the last 100 years and the location and political-administrative situation enjoyed by Chillan since its foundation in 1580 have also affected its residential distribution.

\section{KEYWORDS: HOUSING DYNAMICS, HORIZONTAL} GROWTH, GROWTH FACTORS.

Received: 14.06.14

Accepted: 29.08.14

1 Findings of DIUBB Regular Research Project 124624 3/I "Housing Dynamics in Chillan, 1906 - 2010", funded by the University of Bio Bio, 2012 - 2013.

2 Chile. BA in Geography, Pontifical Catholic University of Chile MSc in Education, ULARE. PhD Candidate in Territorial Planning and Sustainable Development, National University of Cuyo, Argentina. Professor, School of History and Geography, Department of Social Sciences, Faculty of Education and Humanities at the University of Bio Bio. Email: cespinoza@biobio.cl 


\section{Introducción}

La ciudad puede ser entendida desde diferentes aproximaciones epistemológicas: puede ser vista como un fenómeno cambiante, símbolo de un contexto histórico o como la expresión de una sociedad sobre el territorio. La ciudad ha sido abordada como objeto de estudio de la geografía urbana, enfatizando el análisis en las interrelaciones que se dan entre la sociedad y el medio. La geografía busca explicaciones a la expresión espacial que se manifiesta de dichas interrelaciones, basándose en modelos derivados del estudio de patrones y tendencias.

La geografía urbana estudia la morfología, la estructura y las funciones de las ciudades, aportando con ello al proceso de planificación del territorio y a la definición de estrategias de desarrollo urbano que van en beneficio de la sociedad. Asimismo, analiza la ciudad en relación con el entorno regional y nacional, que en cierta forma condiciona su evolución o incide directamente en su configuración.

En esta perspectiva, el análisis geográfico del crecimiento habitacional en Chillán es una de las áreas de estudio de la geografía urbana. Es por esto que en el presente artículo se profundiza en los factores que explican el crecimiento de Chillán, desde principios del siglo XX hasta el año 2013, dado que el año 1906 es cuando por primera vez el Estado de Chile interviene de manera directa en la solución de los problemas habitacionales, mediante la dictación de la Ley $N^{\circ} 1.838$ de Habitaciones para Obreros, llamada de habitaciones baratas, legislación que tuvo como objetivo central dar solución a los problemas sanitarios del proletariado, facilitando para ello el acceso a la vivienda. A partir de dicho año, el Estado de Chile, a través de la promulgación de leyes e implementación de políticas de vivienda, interviene en la distribución social de la población en las áreas urbanas de todo el territorio nacional.

El presente estudio profundiza en diferentes factores que han contribuido en el crecimiento habitacional de Chillán, entre otros: las políticas públicas de vivienda, los modelos de desarrollo económico adoptados por el país, incidencia de los desastres naturales, cambios en el sistema político-administrativo regional y aspectos demográficos.

El estudio pretende contribuir al conocimiento científico en materia de ordenamiento territorial y, particularmente, en el área de la planificación urbana. Por una parte, la investigación tiene por objetivo caracterizar y analizar la dinámica habitacional de Chillán en los últimos 100 años de historia, y por otro lado, identificar y analizar los factores explicativos de la actual configuración de Chillán. 


\section{Objetivo}

Analizar la dinámica habitacional de la ciudad de Chillán durante el periodo 1906-2013, con el fin de identificar factores que expliquen las causas del actual ordenamiento de los espacios residenciales en la ciudad.

\section{Desarrollo}

\section{LOCALIZACIÓN Y CARACTERÍSTICAS GENERALES}

La ciudad de Chillán se localiza en el margen sur de Chile continental, en la Depresión Central, entre los $72^{\circ} 06^{\prime}$ de longitud oeste y los $36^{\circ} 33^{\prime}$ de latitud sur, comprendiendo las áreas urbanas de las comunas de Chillán y Chillán Viejo.

Chillán se emplaza en la depresión intermedia, constituida por depósitos fluviales y fluviovolcánicos del Terciario Superior y Cuaternario. La topografía es predominantemente llana con una leve pendiente, conformada por materiales que han sido transportados desde la cordillera andina por los ríos Chillán y Ñuble, depositados sobre material proveniente de grandes eventos volcánicos y torrenciales. ${ }^{3}$ Es una zona que presenta frecuentes fenómenos sísmicos, dado su emplazamiento en

3 Borgel, 1982
MAPA Nº: UBICACIÓN DE LA CIUDAD DE CHILLÁN

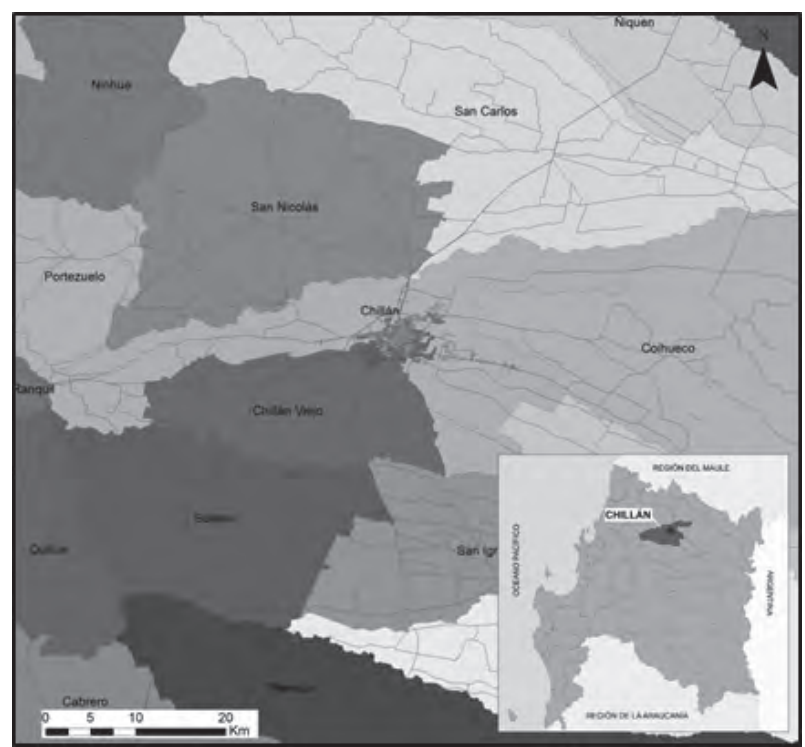

Fuente: Elaboración propia, 2013.

el margen activo de una zona de subducción de placas.

La ciudad de Chillán se caracteriza por la existencia de una variada red hidrográfica, que en su conjunto vienen a formar parte de la cuenca del río Itata. Uno de los principales afluentes del Itata es el río Ñuble, que cruza por el norte la ciudad de Chillán. Por el sur, se desarrolla el río Chillán, 
cuya cabecera se enclava en Los Nevados de Chillán, con un régimen de alimentación pluvio-nival. Además, se desarrollan varios esteros locales que cruzan la ciudad, de los cuales los más importantes son el estero Las Toscas y el Maipo ${ }^{4}$.

\section{Factores históricos y políticas públicas que influyen en la dinámica habitacional de Chillán}

El problema de la vivienda en Chile comenzó a reflejarse a comienzos del siglo XX, cuando aparecen en la morfología urbana los conventillos y ranchos en la ciudad de Santiago, donde moraba la clase social de más escasos recursos.

Existen diversos estudios que dan cuenta del rol que han tenido las políticas de vivienda social en la configuración actual de los espacios residenciales de las ciudades del país, destacando entre ellos las contribuciones realizadas por el Geógrafo Rodrigo Hidalgo. Según este autor "Chile constituye uno de los países de América del Sur que desarrolló en forma más temprana su legislación habitacional. La primera ley chilena que aborda el problema de la habitación popular es la Ley de Habitaciones Obreras de 1906. Este cuerpo legal constituye el punto de partida de un largo

$4 \quad$ Niemeyer y Cereceda, 1984. camino que ha desarrollado este país para aproximarse

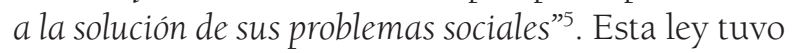
como objetivo central dar solución a los problemas sanitarios del proletariado, facilitando el acceso a la vivienda. "La ley busca garantizar condiciones mínimas de habitabilidad para los pobres de la ciudad, permite demoler muchas construcciones 'insalubres' y en los sectores 'saneados' levantar viviendas 'higiénicas y baratas' para familias solventes, mientras los pobres son expulsados a la periferia".

En 1925 se promulga el Decreto de Ley No 261, conocido como Ley de la Vivienda, posteriormente en 1936 se crea la Caja de la Habitación Popular a través de la promulgación de la Ley 5.950, cuyo objetivo es destinar y gestionar los recursos necesarios para la construcción y el fomento de viviendas salubres y de bajo precio.

Cuando se comienza con este proceso de intervención estatal, en la solución de los "sin casa", Chillán se extendía entre las cuatro avenidas (plano fundacional), junto a la línea del ferrocarril, que llegó a la ciudad en 1870 y del estero Las Toscas. Se desarrollan núcleos periurbanos especialmente al sur del estero, con la existencia de la fábrica de cerveza de Schleyer, una curtiembre y un núcleo religioso en el camino al Pueblo Viejo (actual Chillán Viejo). Existían 28 edificios públicos multifuncionales y 5

5 Hidalgo, 2002, p. 86

6 Ducci, 2007, p. 116. 
plazas (de Armas, San Francisco, La Merced, Santo Domingo y Yungay) ${ }^{7}$.

La ciudad a comienzos del siglo XX se extiende sobre la base del damero clásico, sin mayores alteraciones, para luego ir tomando una forma diferente en torno a un "anillo central", caracterizado por la presencia de múltiples conjuntos habitacionales, lo que origina una difícil conectividad interna y con el área central ${ }^{8}$. Se desarrollan dos áreas urbanas de manera independiente, por un lado Chillán "Nuevo" y, por otro lado, se mantiene Chillán Viejo con su trama fundacional ortogonal, que orientó el crecimiento de esta zona de la ciudad.

Producto de la instalación de las primeras poblaciones obreras, tales como la Población Wicker, Simón Bolívar, Valenzuela Silva y Mardones, hacia 1930 la ciudad se extiende camino a Coihueco, cruza la línea férrea hacia el sector de Ultra Estación y se conecta con el camino viejo (actual Chillán Viejo), con el nacimiento de poblaciones tales como: La Fuente, Chillancito, Santa Rosa, Santa Elvira, Medina y Balmaceda, Villa Alegre, Zañartu, Recinto, Oroguento, Villa Buenos Aires y Avenida O'Higgins.

Chillán para ese entonces sobrepasa los umbrales de las cuatro avenidas, la población alcanzaba los 39.511 habitantes. No obstante, el equipamiento

7 Abarza, Arriagada y López, 2001.

Castillo, Durán, Reyes, Rubilar y Sepúlveda, 1986. urbano no había acompañado este proceso de expansión, siendo severamente deficiente, sólo una minoría de la población dentro de la ciudad era atendida, y esta residía en el sector centro de Chillán. El gran problema que se veía entonces dice relación con que la expansión de la ciudad había sido espontánea, sin ningún tipo de planificación ${ }^{9}$.

Luego del terremoto de 1939, se dicta una Ordenanza Local de Urbanización, que establecía límites urbanos, zonificación, superficie y altura máxima de los edificios, la ciudad de Chillán desde entonces comienza a experimentar un crecimiento más bien horizontal, dando inicio a una nueva etapa expansiva, proceso que marcó la ocupación espacial generando un estilo de desarrollo y predominio a la horizontalidad hacia áreas de crecimiento periféricos ${ }^{10}$.

Chillán, en aquellos años, se estructura a partir de conjuntos habitacionales dispersos y con baja conectividad interior. La presencia de discontinuidades, tales como la línea férrea y cursos de agua al interior de la ciudad, determinaron un crecimiento irregular, que pone fin a la predominancia del plano ortogonal que caracteriza a las áreas fundacionales de Chillán y Chillán Viejo.

El año 1952 se realiza el Censo de Vivienda, que deja en evidencia el grave problema habitacional

9 Abarza, Arriagada y López, 2001.

10 Miranda, 2010. 
que vivía el país. Se comienza a hablar de "políticas habitacionales" o "planes de vivienda", entendiéndose ya como un problema nacional, para lo que había que establecer leyes acordes a la situación. En 1948 se dicta la Ley Pereira, que promueve la construcción de viviendas para la clase media. En 1950 los conflictos por el acceso al suelo urbano se hacen cada vez más evidente, por el aumento de la migración campo-ciudad, incentivado por la industrialización, el nuevo modelo económico imperante de sustitución de importación y la creación de la CORFO (Corporación de Fomento de la Producción) a través de la Ley N 6.640 publicada el 10 de enero de 1941.

El año 1953, el Gobierno de Carlos Ibáñez del Campo crea la Corporación de Vivienda (CORVI), mediante el Decreto Ley N²85, que fusionó la Caja de Habitación y la Corporación de Reconstrucción y Auxilio. El objetivo fundamental de la CORVI fue la construcción de viviendas económicas, así como la urbanización, reconstrucción y remodelación de barrios y sectores comprendidos en el Plan de Vivienda (Arts. N² y 3 Ley N²85).

Durante la década del 50' Chillán experimenta una fuerte migración campo-ciudad, que rompe la uniformidad de la ciudad, urbanizándose los intersticios de su damero original. Se incrementa la expansión hacia los distintos puntos del plano

ARTíCULO: Dinámica habitacional en Chillán, Chile (1906 - 2013) / Claudia Paola Espinoza Lizama fundacional, generándose "anillos externos", que también ocupan predios agrícolas, siendo este el primer paso a la urbanización de sectores rurales. Comenzaron a formarse las llamadas poblaciones callampas, consideradas como unos verdaderos "basureros", en donde los sectores pobres de la población construían sus medias aguas con los materiales de desecho. Uno de los sectores de Chillán más típico al respecto, es la llamada población el Saque, bajo el puente del mismo nombre, en la salida este de Chillán, en el llamado camino a las Termas ${ }^{11}$.

En 1959 surge el Plan Habitacional DFL-2, del Decreto con Fuerza de Ley $N^{\circ} 2$, dictado en el gobierno del presidente Jorge Alessandri Rodríguez, el cual fomentaba la construcción habitacional, excluyendo de impuestos a los terrenos destinados a viviendas, además de rebajas tributarias a las constructoras de viviendas, por lo que durante este período crecen las empresas inmobiliarias del país.

Desde 1964 hasta 1972 se intensificaron las "tomas de terreno" en el país, situación que se abordó con estrategias que intentaron frenar dicho fenómeno a través de la implementación del programa de Operación Sitio, entre los años 1965 y 1970, y luego desde 1970 hasta 1973 con el PAP, Plan de Ahorro Popular para adquirir la vivienda propia más un subsidio del Estado. Además, el año 1965 se creó el

11 Sepúlveda y Espinoza, 2011. 
Ministerio de Vivienda y Urbanismo (MINVU), el cual posteriormente reemplazará a la CORVI.

Es así como durante la década de los 60’ y hasta el año 1973, en Chile más de 400.000 familias accedieron a la tierra mediante la "ocupación irregular" de terrenos, como una de las estrategias principales para acceder a la vivienda.

Así surgen en Chillán sectores habitacionales que en la actualidad se encuentran consolidados, tales como las emblemáticas poblaciones Vicente Pérez Rosales y Luis Cruz Martínez. Las tomas de terreno fueron mecanismos utilizados por familias que aún habitaban en pabellones de emergencia construidos por el presidente Pedro Aguirre Cerda, tras el terremoto de 1939 en Chillán.

Posteriormente, las políticas de vivienda en Chile son marcadas por la llegada al poder del gobierno militar en 1973. Surge una nueva política de vivienda, marcada por el neoliberalismo, y tendencias privatizadoras. Con estos hechos, el ritmo de producción de viviendas destinadas a hogares pobres se reduce marcadamente, entre los años 1974 y 1978, culminándose solo los proyectos iniciados bajo el gobierno de Salvador Allende.

Con la creación del MINVU nacen los planes reguladores comunales y las políticas de desarrollo urbano, siendo una de las primeras la Política de Desarrollo Urbano Metropolitano y luego en 1979, la Política Nacional de Desarrollo Urbano (PNDU), orientada a liberar las trabas del suelo urbano al mercado, además de reactivar los programas de acceso a las viviendas de clases medias y los más vulnerables, incentivando para ello la inversión privada y la renuncia a la política de vivienda pública. Ahora el Estado desarrolla un papel central en el financiamiento de la vivienda, apoyando el acceso a la propiedad, pero no su construcción ${ }^{12}$. Se inicia así, un sistema de subsidio habitacional que gradualmente comenzó a desarrollar programas de vivienda, principalmente para aquellos sectores más pobres, a lo que cabe incluir también, la dotación de servicios básicos para los hogares ${ }^{13}$. "En 1979, con la promulgación de la nueva Política Nacional de Desarrollo Urbano (PNDU) por el gobierno del general Pinochet, el modelo liberal se aplicó a la planificación urbana, gracias a una apertura del mercado inmobiliario. Desde entonces el estado liberal buscó dejar importantes márgenes de maniobra al mercado inmobiliario y favorecer un desarrollo urbano excesivo para la aglomeración. Se afirmó que el suelo no era un recurso limitado y que la función del mercado es encontrar el tamaño óptimo de la ciudad y definir el empleo del suelo". ${ }^{14}$ 
La expansión urbana experimentada por Chillán y Chillán Viejo desde 1978 al año 2000, ha sido la más alta de su historia. En este periodo de 22 años, se ocuparon 932 hectáreas de suelos agrícolas. Ocupación que se vio favorecida, por la desregulación que se produjo con la Política de Desarrollo Urbano de 1979 que permitió a las inmobiliarias transar en el libre mercado los suelos agrícolas, que fueron incorporados al uso urbano al margen del Plan Regulador, eliminándose los límites al crecimiento urbano, al punto que existen predios en la categoría de urbano, pero que todavía mantienen el rol rural ${ }^{15}$.

Durante la década de los noventa, el Ministerio de Vivienda y Urbanismo (MINVU) comienza con un programa llamado "Operación Barrio" para acabar con los campamentos del país. Es así como en el año 1996, ya 260.000 familias chilenas de escasos recursos tenían una solución habitacional, a través de este proceso acelerado de asistencialismo social habitacional ${ }^{16}$. El sistema de producción de viviendas sociales a los sectores más vulnerables de la sociedad se caracterizó por la baja de los estándares en la calidad de la vivienda, entregando viviendas con superficies construidas de tan solo $32 \mathrm{~m}^{2}$, lo cual significa que la política de vivienda, en los primeros años priorizó la cantidad por sobre la calidad de las soluciones, afectando directamente la

15 Henríquez M., 2006.

16 Ducci, 1998. calidad de vida de la población más vulnerable de la sociedad ${ }^{17}$.

Debido a esto, comienza a hacer crisis la política de vivienda imperante hasta ese momento: "la política habitacional chilena empieza a complicarse cuando, en 1997, debido a una fuerte temporada de lluvias, la mala calidad de las viviendas se hace evidente y explota una crisis que no ha podido ser zanjada hasta ahora. Las imágenes de edificios cubiertos por gigantescas mangas de plástico para intentar detener el agua que inundaba las viviendas fueron mostradas profusamente por los medios y han pasado al imaginario nacional como las 'casas de plástico', símbolo de la pésima calidad de las viviendas producidas por el Estado". ${ }^{18}$

En Chillán este fenómeno se evidencia en la construccion de una cantidad importante de viviendas sociales en la periferia oriente y suroriente de la ciudad, construyéndose a partir del año 1990, todas las etapas de la población Los Volcanes, ícono de la vivienda social en Chillán.

Un documento del año 2007, elaborado por Brain, Cubillos y Sabatini, que trata sobre la nueva política habitacional impulsada por el gobierno de la presidenta Michelle Bachelet, haciendo alusión a las políticas de vivienda, señala que ahora se debe "(i) disminuir el déficit habitacional, focalizando en las familias que viven en pobreza; (ii) garantizar la calidad

17 Ducci, 1997.

18 Ducci, 2007, p. 110. 


\section{TABLA N^1: AÑo DE CONSTRUCCIÓN DE LOS CONJUNTOS HABITACIONALES EN CHILLÁN}

\begin{tabular}{|c|c|}
\hline Año & Poblaciones \\
\hline $1880-1920$ & $\begin{array}{l}\text { Población Wicker, Simón Bolívar, Valen- } \\
\text { zuela Silva, Mardones. }\end{array}$ \\
\hline 1930 & $\begin{array}{l}\text { La Fuente, Chillancito, Santa Rosa, Santa } \\
\text { Elvira, Medina y Balmaceda, Villa Alegre, } \\
\text { Zañartu, Recinto, Oroguento, Villa Buenos } \\
\text { Aires, Avenida O'Higgins }\end{array}$ \\
\hline 1939 & $\begin{array}{l}\text { Pabellones de emergencia Estadio, Rodrí- } \\
\text { guez, O'Higgins }\end{array}$ \\
\hline 1943 & Defensa Nacional, Centenario. \\
\hline 1949 & Sargento Aldea, Collín. \\
\hline 1950 & Población Ibáñez. \\
\hline 1953 & Rosita O'Higgins, Marta Brunet. \\
\hline 1955 & La Fuente, Medina \\
\hline 1958 & 20 de agosto, Población Pedro Lagos \\
\hline 1959 & Población Bartolucci, El tejar \\
\hline 1960 & Población Ortega, Pedro Lagos II \\
\hline 1961 & $\begin{array}{l}\text { El Roble, Población Purén, Defensa } \\
\text { Nacional. }\end{array}$ \\
\hline 1962 & Juan XXIII, Irene Frei y Planificadores. \\
\hline 1963 & Población Purén II. \\
\hline 1965 & Población Kennedy \\
\hline 1967 & Ferretera. \\
\hline 1968 & $\begin{array}{l}\text { IANSA (frente a Av. Argentina), ENDESA, } \\
\text { Olalde, Prado. }\end{array}$ \\
\hline 1969 & $\begin{array}{l}\text { El Toro, Empleados Municipales, Santa } \\
\text { Eugenia, El tejar, La Araucana, Conjunto } \\
\text { Habitacional Ñuble. }\end{array}$ \\
\hline
\end{tabular}

\begin{tabular}{|c|c|}
\hline Año & Poblaciones \\
\hline 1971 & $\begin{array}{l}\text { Vicente Pérez Rosales, Luis Cruz } \\
\text { Martínez, Arturo Prat, Mallín del Sol, } \\
\text { SOCOAGRO. }\end{array}$ \\
\hline 1973 & $\begin{array}{l}\text { Villa Ferroviaria, Coihueco (frente a Chi- } \\
\text { chancito), } 11 \text { de Septiembre. }\end{array}$ \\
\hline 1976 & Villa Olímpica, Sarita Gajardo. \\
\hline 1978 & $\begin{array}{l}\text { Mallines del sol, Villa Ferrocar, Socoagro, } \\
\text { Purén, El Tejar } 2 .\end{array}$ \\
\hline 1980 & $\begin{array}{l}\text { Departamentos Santa Marta, Población } \\
\text { Bartolomé, Población Bicentenario. }\end{array}$ \\
\hline 1983 & Cuarto Centenario, Los Andes. \\
\hline 1984 & Villa el Sol. \\
\hline 1985 & Villa Antuco, Los Puelches. \\
\hline 1986 & Villa Chiloé. \\
\hline 1987 & Población Río viejo. \\
\hline 1988 & Población Río viejo $2^{a}$ etapa. \\
\hline 1989 & 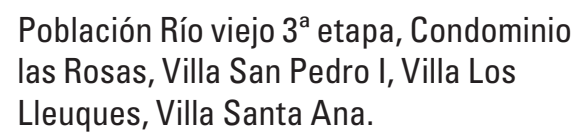 \\
\hline 1990 & $\begin{array}{l}\text { Población Río viejo } 5^{\text {a }} \text { etapa, Los Vol- } \\
\text { canes I, Santa Teresa, Villa Palermo, } \\
\text { Huichilles. }\end{array}$ \\
\hline 1991 & $\begin{array}{l}\text { Conjunto Residencial Asturias, Villa el } \\
\text { Bosque, Volcanes II, Población Río viejo } \\
5^{\text {a }} \text { etapa, Villa Ramón Vinay, Oscar Boni- } \\
\text { Ila, Huambalí, Pedro Aguirre Cerda. }\end{array}$ \\
\hline
\end{tabular}




\begin{tabular}{|c|c|}
\hline Año & Poblaciones \\
\hline 1992 & $\begin{array}{l}\text { Villa Los Pinos, Villa Los Olivos, Villa } \\
\text { Padre Hurtado I, Volcanes III, Volcanes } \\
\text { IV, Población Río viejo } 6^{\text {a }} \text { etapa, Santa } \\
\text { Filomena, Villa Río Las Lilas. }\end{array}$ \\
\hline 1993 & $\begin{array}{l}\text { Villa Los Copihues, Villa Los Aramos, } \\
\text { Volcanes V, Jardines de Ñuble, Jardines } \\
\text { del Este, Villa San Cristóbal, Volcanes VII, } \\
\text { Ruíz de Gamboa. }\end{array}$ \\
\hline 1994 & $\begin{array}{l}\text { Ruíz de Gamboa } 2^{\text {a }} \text { etapa, Volcanes VIII, } \\
\text { Volcanes IX, Villa Alpina, Parque Arauco, } \\
\text { Villa Belén. }\end{array}$ \\
\hline 1995 & $\begin{array}{l}\text { Ruíz de Gamboa } 3^{\text {a }} \text { etapa, Emanuel } \\
\text { Ampliación, Parque Lantaño, Vicente } \\
\text { Méndez. }\end{array}$ \\
\hline 1996 & $\begin{array}{l}\text { Villa La Arboleda, Villa Los Copihues, } \\
\text { Villa Los Naranjos de Castilla, Villa Padre } \\
\text { Hurtado II, Villa Las Américas, Volcanes } \\
\text { VI, Lomas de Oriente I, Lomas de Orien- } \\
\text { te II, Condominio Nuble, Rupanco, Las } \\
\text { Américas. }\end{array}$ \\
\hline 1997 & $\begin{array}{l}\text { Villa Los Chiquillanes, Villa El Sembrador, } \\
\text { Villa la Pradera, Villa Betania, Condomi- } \\
\text { nio la Pradera, Portal del Ñuble-Bartoluc- } \\
\text { ci, Lomas de Oriente III, Lomas de Oriente } \\
\text { IV, Los Poetas, Villa Precordillera, Jardi- } \\
\text { nes del Sur, Villa Quilmo, Villa Galilea. }\end{array}$ \\
\hline 1998 & $\begin{array}{l}\text { Villa Padre Hurtado III, La Pradera, Santa } \\
\text { Marta I y II, Villa Monterrico I, Lomas de } \\
\text { Oriente VI, Lomas de Oriente VII, Villa } \\
\text { Robinson Ramírez. }\end{array}$ \\
\hline
\end{tabular}

ARTíCULO: Dinámica habitacional en Chillán, Chile (1906 - 2013) / Claudia Paola Espinoza Lizama

\begin{tabular}{|c|c|}
\hline Año & Poblaciones \\
\hline 1999 & $\begin{array}{l}\text { Villa Los Naranjos de Castilla, Condo- } \\
\text { minio Don Eduardo I, Villa Monterrico II, } \\
\text { Condominio El Otoñal I y II, Villa Esmeral- } \\
\text { da, Comunidad San Miguel y San José. }\end{array}$ \\
\hline 2000 & $\begin{array}{l}\text { Villa Virrey Don Ambrosio, Villa Los } \\
\text { Colihues, Villa Los Naranjos de Castilla, } \\
\text { Alcalde Navas, Villa Santa María, Villa } \\
\text { Emaús, Villa Galilea ampliación, Condo- } \\
\text { minio Millantue, Estación Quilamapu, } \\
\text { Villa Doña Isabel, Villa las Crisálidas, } \\
\text { Doña Francisca I, Ampliación Villa San } \\
\text { Cristóbal. }\end{array}$ \\
\hline 2001 & $\begin{array}{l}\text { Población Bellavista, Villa Ríos del Sur, } \\
\text { Ruiz de Gamboa } 4^{\mathrm{a}} \text { etapa, Doña Francisca } \\
\text { II, Islas del Sur, Barcelona, Villa Padre } \\
\text { Hurtado I y II, Paseo de Aragón, Lomas } \\
\text { V, Nuevo Amanecer, Ruíz de Gamboa } \\
\text { Ampliación. }\end{array}$ \\
\hline 2002 & $\begin{array}{l}\text { Villa Eduardo Frei, Villa Los Naranjos de } \\
\text { Castilla, Parque Habitacional Río Viejo } \\
1^{\mathrm{a}} \text { etapa, Villa Universitaria, Condominio } \\
\text { Don Eduardo III, Villa Paraíso. }\end{array}$ \\
\hline 2003 & $\begin{array}{l}\text { Villa Los Naranjos de Castilla, Villa Los } \\
\text { Aromos, Villa Los Olivos, Brisas del } \\
\text { Oriente, Los Evangelistas, Villa Sargento } \\
\text { Aldea, Doña Francisca III A, Brisas del } \\
\text { Valle I. }\end{array}$ \\
\hline 2004 & $\begin{array}{l}\text { Villa Los Naranjos de Castilla, Villa Olim- } \\
\text { po, Brisas del Volcán, Doña Francisca III } \\
\text { B, Doña Francisca III C. }\end{array}$ \\
\hline
\end{tabular}

revista invi № 82 / Noviembre 2014 / Volumen № 29: 157-187 167 


\begin{tabular}{|c|c|}
\hline Año & Poblaciones \\
\hline 2005 & $\begin{array}{l}\text { Villa Ríos del Sur, } 20 \text { de agosto, Con- } \\
\text { dominio el Madrigal, Condominio San } \\
\text { Alfonso, Villa Laguna de España, Nevado } \\
\text { I, Nevado II, Brisas del Nevado, Brisas de } \\
\text { Chillán, Parque Lantaño. }\end{array}$ \\
\hline 2006 & $\begin{array}{l}\text { Brisas del valle II, Villa Río Chillán, Flores } \\
\text { Millán, Condominio Aranjuez, Condomi- } \\
\text { nio Altamira (Santa Marta III), Las Came- } \\
\text { lias del Poniente, Villa Doña Josefina. }\end{array}$ \\
\hline 2007 & $\begin{array}{l}\text { Villa Los Dominicos, Villa Diego Portales, } \\
\text { Portal del Sol I, Portal del Sol II, Villa } \\
\text { Doña Rosa 1a etapa. }\end{array}$ \\
\hline 2008 & $\begin{array}{l}\text { Villa Padre Pío, Villa Ríos del Sur, Las } \\
\text { Higueras, Villa Diego Portales, Villa Doña } \\
\text { Rosa } 2^{\mathrm{a}} \text { etapa, Villa San Miguel, Condo- } \\
\text { minio Yotaú, Condominio Andrés Bello, } \\
\text { Barrio Toledo, Condominio San Alberto, } \\
\text { Brisas de Nuble I y II, Parque habitacio- } \\
\text { nal Río Viejo } 2^{\mathrm{a}} \text { etapa, Brisas del Valle III } \\
\text { y IV. }\end{array}$ \\
\hline 2009 & $\begin{array}{l}\text { Villa Ríos del Sur, Villa San Esteban I, } \\
\text { Villa Diego Portales, Portal del Sol I, Con- } \\
\text { dominio los Tajibos, Condominio Sirarí, } \\
\text { Santa Rufina, Los Lagos de Chile, Valle } \\
\text { Hermoso de Quilmo, El Sauce. }\end{array}$ \\
\hline
\end{tabular}

Año

\section{Poblaciones}

Villa Hacienda Los Fundadores, Villa Ríos del Sur, Villa San Esteban II, Los Conquistadores, Resplandor, Resplandor 2, Las Orquídeas, Portal del Libertador, Condominio Los Tepuys I y II.

Villa San Esteban III, Departamentos en calle 20 de agosto, Portal del Libertador II, Condominio Guapurú, Villa Schangrilá I y II, Condominio Altamira Ampliación.

Departamentos Jaun Martínez de Rozas, Cayumanqui I, II, III, Portal Libertadores segunda etapa, San Agustín, Valle Central, Condominio Plaza Real, Condominio El Ávila, Los Dominicos, Santa Rufina I, Villa La Higuera, Villa San Esteban, Villa La Esperanza.

\begin{tabular}{ll}
\hline & Departamentos Luis Araneda, Santa \\
& Rufina II, Doña Rosa C, Brisas del Bicen- \\
& tenario, Verde Parque, Edificio Andes de \\
Chillán, Hacienda Los Fundadores, Fundo \\
Santa Rita.
\end{tabular}

Fuente: Archivos Departamento de Loteos y Subdivisión. DOM, Municipalidades de Chillán y Chillán Viejo, 2013. 
de las viviendas, mejorando su estándar y los procesos de diseño y construcción; y (iii) promover la integración social, procurando soluciones habitacionales insertas en barrios y ciudades." 19

Mejorar la calidad de la vivienda es un nuevo objetivo de la política habitacional, además de la integración social urbana o residencial, lo que es particularmente crítico en las grandes ciudades y un heredado a las ciudades intermedias como Chillán. Resulta evidente que la necesidad de integrar socialmente a las familias en barrios y en ciudades con acceso a trabajo, a equipamientos, servicios, entre otros, es fundamental para evitar la generación de procesos de segregación socio-espacial.

En una "mirada" más global sobre las investigaciones del crecimiento urbano, en general diversos autores coinciden en que el crecimiento de las ciudades (planificado o no) ha generado una creciente segregación socio-espacial, caracterizada por la desintegración social. En esta línea de análisis, el sociólogo Francisco Sabatini ha desarrollado importantes investigaciones sobre planificación urbana, mercado de suelo, segregación socio-espacial e integración social urbana. Al respecto, en un trabajo realizado en conjunto con Isabel Brain ${ }^{20}$, analiza la segregación y la integración social, planteando que "no existen impedimentos culturales, sociológicos ni económicos para conseguir

19 Brain, Cubillos y Sabatini, 2007, p. 18.

20 Sabatini y Brain, 2008. menores grados de segregación social del espacio en las ciudades latinoamericanas, objetivo que debe ocupar un lugar crítico en la política pública, considerando que los barrios populares segregados se están "guetizando" (drogas, crimen y deserción escolar, entre otros problemas)" ${ }^{\prime 21}$. En esta perspectiva, y en la misma línea de reflexión, la segregación socio-espacial, aunque parezca contradictorio, es en parte el resultado de la planificación urbana normativa y restrictiva, en donde las densidades habitacionales destinan zonas, habitualmente periféricas de las ciudades, para el desarrollo de vivienda social, lo que ha imperado en la planificación urbana de la ciudad Chillán, manifestándose en el crecimiento horizontal de la ciudad con evidentes grados de segregación socio-espacial.

Al respecto, Azócar, Sanhueza y Henríquez, haciendo alusión a Chillán plantean que "la dinámica del cambio nos muestra la importancia del uso residencial en el crecimiento de la ciudad y la existencia de un proceso urbano de segregación espacial. Es así como el cambio urbano con altas densidades está asociado a zonas pobres $y$ vulnerables, mientras el cambio con baja densidad, a zonas no pobres y segmentos de población de ingresos medios-altos. La población de ambas zonas presenta diferentes perfiles socioeconómicos, que a su vez reflejan diferentes patrones de localización en contextos especificos de paisaje"22

21 Ibíd., p. 19.

22 Azócar, Sanhueza y Henríquez, 2003, p. 92. 
Henríquez y Azócar realizan una propuesta de modelos predictivos en la planificación territorial y evaluación de impacto ambiental en la ciudad de Chillán, en el que concluyen que "[...]Los resultados del modelo muestra que en los últimos 28 años el área urbana de Chillán aumentó un 86,7\%, es decir pasó de 1.504 há en 1978 a 2.809 há en 2006. Este crecimiento se ha concentrado fundamentalmente en la parte nororiente de la ciudad. Mientras que la simulación realizada para el periodo 2006 - 2034 estima un crecimiento futuro de 69\%"23.

Anabalón señala que "las formas de crecimiento urbano, asociados a los procesos económicos, sociales y políticos más globales, han contribuido a modelar una ciudad con fuertes contrastes sociales y con severos problemas ambientales. Más bien deberíamos hablar de tres ciudades en una: la primera denominada histórica o del casco antiguo, ubicada entre las cuatro avenidas y en Chillán Viejo; la ciudad de los pobres, en la parte sur oriente; y la nueva ciudad segregada o de oportunidades, en la parte nororiente". ${ }^{24}$

La población de altos ingresos, se localiza en el sector noreste y este de la ciudad, en tierras con vocación agrícola, encontrándose conjuntos habitacionales y viviendas unifamiliares de lujo con superficies superiores a $1.000 \mathrm{~m}^{2}$ construidos, amplios jardines y patios, junto a áreas que concentran las principales instituciones de educación

23 Henríquez y Azócar, 2007, p. 25

24 Anabalón, 2006, p. 90. media particulares, subvencionadas y universitaria pública y privada, en un "entorno rural de privilegio, con buen acceso vial, sin contaminación acústica ni atmosférica"25. Actualmente, dichos procesos de expansión urbana continúan con inversiones de gestores inmobiliarios privados, mediante la construcción de condominios (ley de copropiedad), en suelos otrora agrícolas.

Los sectores más pobres, constituidos por asentamientos precarios excluidos del proceso económico, han sido relegados a tierras marginales social y ambientalmente, de menor valor, en las riberas de esteros, canales y ríos. Ejemplo son el asentamiento Las Habas en el Puente Lazareto y Callejón Maipón en el Puente Barrio Chino del estero Las Toscas, y el Saque en población Río Viejo en el río Chillán.

Según los registros de loteos para la construcción de poblaciones nuevas, que lleva la Direcciones de Obras (DOM) de las Municipalidades de Chillán y Chillán Viejo, se produce un incremento en la construcción de poblaciones o loteos habitacionales tras el terremoto del año 1939.

La historia del crecimiento habitacional de la ciudad de Chillán está marcado por los desastres naturales, puesto que el registro de las edificaciones nuevas en la ciudad de Chillán se comienza

25 Olave, 1994 
TABLA N 2: ETAPAS DEL CRECIMIENTO HABITACIONAL DE LA CIUDAD DE CHILLÁN

\begin{tabular}{ll} 
Períodos de crecimiento & $\begin{array}{l}\mathrm{N}^{\circ} \text { de poblaciones, } \\
\text { conjuntos o villas }\end{array}$ \\
\hline $1835-1939$ & 19 \\
\hline $1939-1989$ & 42 \\
\hline $1990-2013$ & 142 \\
\hline
\end{tabular}

Fuente: DOM Municipalidades de Chillán y Chillán Viejo, 2013.

a realizar solo a partir de 1940, debido a que el terremoto de 1939 quemó los archivos guardados en la repartición municipal de la época.

El 91\% de la viviendas correspondientes a loteos habitacionales nuevos, que se construyeron después del año 1990, como consecuencia directa de las nuevas políticas habitacionales impulsadas por el Gobierno de Eduardo Frei Ruiz-Tagle, y el acceso del mercado a las tierras, promovido por el modelo económico neoliberal imperante en el país desde 1974. Durante los años 1970 hasta 1979, cuando se promulga la Política Nacional de Desarrollo Urbano (PNDU) para liberar las trabas del suelo urbano al mercado, además de reactivar los programas de acceso a las viviendas de clases medias y los más
TABLA N 3: PERMISOS DE EDIFICACIÓN HISTÓRICOS EN LA CIUDAD DE CHILLÁN

\begin{tabular}{lcc} 
Periodo & $\mathrm{N}^{\circ}$ Permisos Edificación & $\%$ \\
\hline $1940-1949$ & 787 & 1,75 \\
\hline $1950-1959$ & 330 & 0,73 \\
\hline $1960-1969$ & 592 & 1,32 \\
\hline $1979-1989$ & 2.068 & 4,59 \\
\hline $1990-1999$ & 14.853 & 33,00 \\
\hline $2000-2009$ & 17.336 & 38,52 \\
\hline $2010-2013$ & 9.040 & 20,09 \\
\hline Total & 45.006 & 100,00 \\
\hline
\end{tabular}

Fuente: Archivo DOM Municipalidades de Chillán y Chillán Viejo, 2013.

vulnerables, no se registraron construcciones de viviendas nuevas en Chillán.

El registro de los permisos de edificación da cuenta de un aumento sostenido en el número de viviendas construidas en la ciudad de Chillán, fundamentalmente a partir del año 1990. En dicha década se construyeron 14.853 viviendas, correspondientes a unidades en conjuntos habitacionales, representando un 33\% del total de los permisos de edificación emitidos.

En el periodo 2000-2009, se construyeron un total de 17.336 viviendas, siendo la década con mayor crecimiento habitacional, representando un 38,52\% de los permisos de edificación otorgados por la municipalidad de Chillán y Chillán Viejo. 


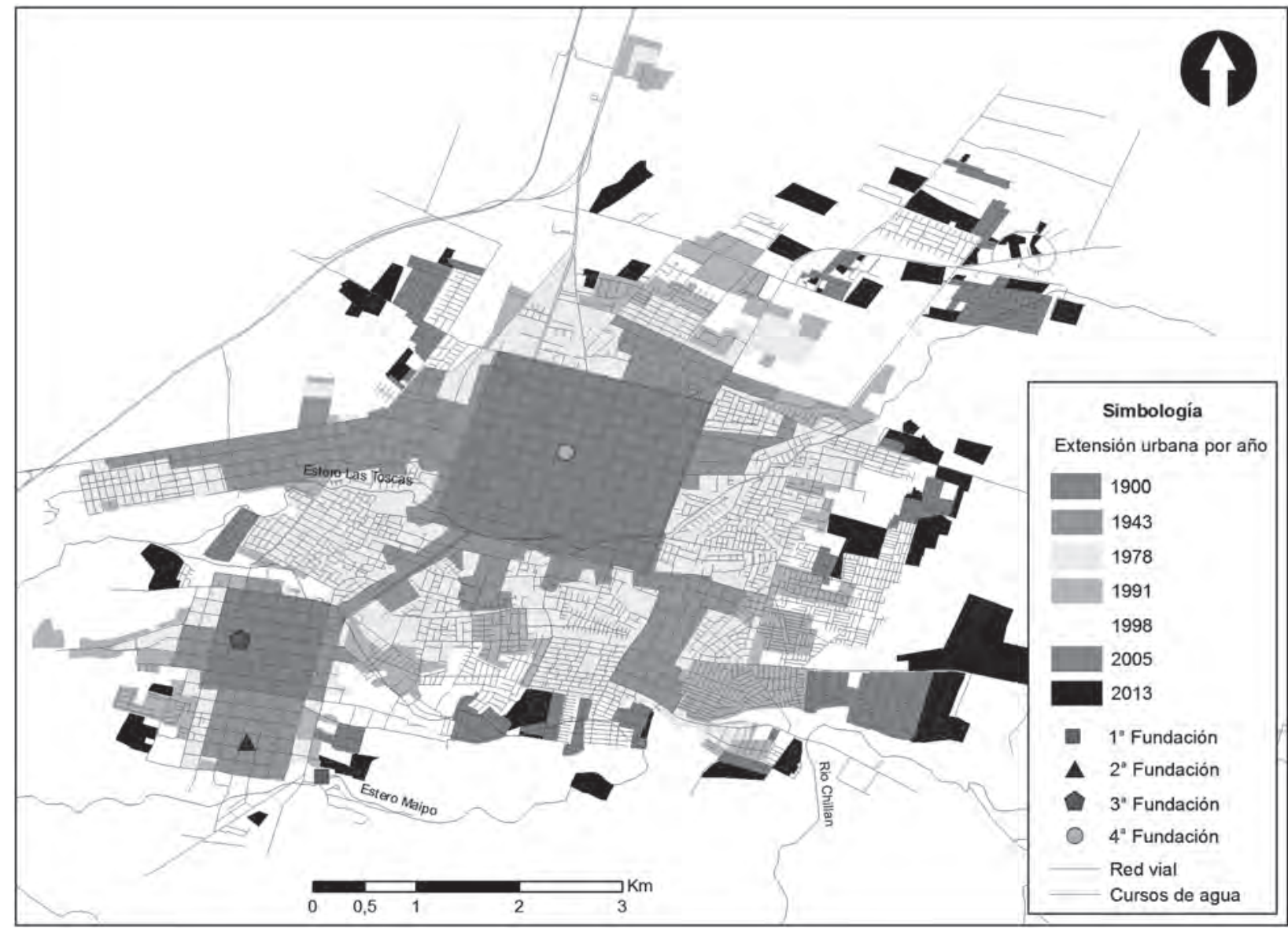

Fuente: Imagen satelital Google Earth del periodo 2003 a 2013 y fotografía aéreas del SAF período 1943 a 1998. 
TABLA N ${ }^{\circ}$ 4: SUPERFICIE DEL CRECIMIENTO HABITACIONAL DE LA CIUDAD DE CHILLÁN

\begin{tabular}{lll}
\hline Año & Há & Crecimiento Há \\
\hline 1900 & 379 & \\
\hline 1943 & 816 & 437 \\
\hline 1978 & 1.510 & 694 \\
\hline 1991 & 1.839 & 329 \\
\hline 1998 & 2.185 & 346 \\
\hline 2005 & 2.379 & 194 \\
\hline 2013 & 2.624 & 245 \\
\hline
\end{tabular}

Fuente: Elaboración propia, 2013.

Entre los años 2010 y 2013, en solo 4 años, se registra un total de 9.040 permisos de edificación, correspondiendo el 20,09\% del total de los permisos de edificación. Esto a consecuencia de la inversión realizada por el Gobierno de Chile en la reconstrucción de viviendas posterior al terremoto del 27 de febrero de 2010.

Esta dinámica habitacional generó un crecimiento predominantemente horizontal, hacia la periferia de la ciudad, tal como se observa en el siguiente mapa. Los nuevos conjuntos habitacionales, cada vez se emplazan en predios periurbanos, más alejados del centro comercial, administrativo y de servicios de la ciudad de Chillán, por lo que las nuevas áreas residenciales presentan problemáticas urbanas tales como: congestión vehicular en horarios puntas, por la falta de alternativas viales, déficit y dificultades en el acceso a equipamientos, y en general mayores tiempo de viajes en los desplazamientos.

En el periodo 1943-1978, Chillán aumentó en 437 hectáreas, entre 1978 y 1991 la ciudad prácticamente duplicó su superficie, incrementándose en 694 hectáreas. No obstante, el mayor crecimiento se registra a partir del año 1991, con un aumento de 1.114 hectáreas entre dicho año y el 2013.

El mapa precedente refleja el fuerte crecimiento habitacional de Chillán durante los últimos 20 años, con un marcado emplazamiento de los nuevos conjuntos habitacionales en la periferia de la ciudad, a pesar de existir terrenos "vacantes" posibles de urbanizar al interior de la trama urbana.

\section{El factor económico y su influencia en la dinámica habitacional de Chillán}

Después de la gran depresión de 1929 el Estado de Chile adopta una nueva política económica orientada a un desarrollo hacia adentro, donde se sustituyen las importaciones, se establecen controles de cambio, se aumentan las tarifas aduaneras y otras barreras arancelarias, principalmente para dar respuesta a las necesidades del mercado interno, generándose consigo un cierre de la economía, 
protegiendo e incentivando la industria tradicional. Complementario a estas medidas, se crea la CORFO el año 1941, alcanzando logros en los distintos sectores productivos por medio de la ejecución de grandes proyectos en áreas eléctricas, siderúrgicas, petrolera y agroindustrias, produciéndose un despegue de la economía nacional, llegando este modelo a su fin cuando se implementan en 1974 las nuevas políticas económicas basadas en el modelo neoliberal.

Producto de la adopción de estas políticas orientadas al desarrollo industrial, comienza a generarse un crecimiento de los centros urbanos que cuentan con instalaciones industriales preexistentes, localizadas principalmente en el eje costero de la región, específicamente en la zona de Concepción y Talcahuano, fortaleciéndose también las ciudades intermedias. En este escenario, Chillán se vio favorecida, recibiendo inversiones en el área de la agroindustria, que gatillaron movimientos migratorios campo-ciudad. Desde el año 1950 en adelante, se configura un cordón industrial en el acceso norte a la ciudad, en torno a la avenida O'Higgins. Se instalan empresas estales como IANSA (Industria Azucarera Nacional) en la ruta 5 Sur, que genera encadenamientos productivos con el sector agrícola, demandando grandes cantidades de remolacha.

174 revista invi № 82 / Noviembre 2014 / Volumen No 29: 157-187
Este modelo genera la gran migración de la población campo-ciudad en busca de puestos laborales en la floreciente industrialización, lo cual trató de solucionarse el año 1962 mediante la implementación de las reformas agrarias, "con el fin de reestructurar la tenencia de la tierra y mejorar la baja productividad de la agricultura nacional. A pesar de los esfuerzos realizados por el Estado a través de la reforma agraria, esta no alcanzó las metas fijadas, ya que a pesar de haber logrado para el año 1969 un aumento en un 60\% de las tierras cultivables, el $80 \%$ de estas correspondian a terrenos de secano (de 3.400.000 has., 2.800 .000 eran de secano), las cuales por su baja productividad no dan el impulso necesario para la reactivación de la economía agraria, y por ende los centros urbanos ligados a la actividad agricola mantenían un crecimiento menor con relación a aquellos vinculados a dicha actividad"26.

En el contexto de la crisis del modelo industrial sustitutivo y su reemplazo por el modelo neoliberal, adoptado por el gobierno militar en 1974, se abre nuevamente la economía chilena al mundo, insertándose en la economía internacional, por el estímulo y diversificación de las exportaciones bajo el principio de ventajas comparativas, provocando una reducción de la producción nacional. Este cambio de modelo afectando la actividad industrial y las áreas dependientes de éstas, beneficiando las actividades primarias como la minería

26 Reyes, 2000, p. 41. 


\section{TABLA N 5: EVOLUCIÓN DE LOS MODELOS ECONÓMICOS APLICADOS EN CHILE}

\begin{tabular}{|c|c|c|}
\hline Año & Modelo & Observaciones \\
\hline 1900-1930 & Exportador. & $\begin{array}{l}\text { Se exportaban productos no elaborados, principalmente recursos naturales } \\
\text { como el cobre y el salitre. }\end{array}$ \\
\hline 1930-1973 & $\begin{array}{l}\text { Modelo de economía } \\
\text { del bienestar, modelo } \\
\text { keynesiano. }\end{array}$ & $\begin{array}{l}\text { - Estado empresario. } \\
\text { - Fuerte influencia del Estado en el desarrollo económico. } \\
\text { - Industrialización por Sustitución de Importaciones (ISI) } \\
\text { - Creación de la Corporación de fomento (CORFO) en } 1941 \text { Ley } 6640 . \\
\text { - 1962: Reforma Agraria. } \\
\text { - En } 1970 \text { nacionalización del cobre. } \\
\text { - Nacimiento de industrias nacionales. }\end{array}$ \\
\hline 1973- 1983 & $\begin{array}{l}\text { Modelo económico } \\
\text { neoliberal, centrado en } \\
\text { la desregulación. }\end{array}$ & $\begin{array}{l}\text { - Rol subsidiario del Estado, sólo interviene en actividades productivas y de } \\
\text { servicios cuando los privados no lo hacen. } \\
\text { - La planificación de la desregularización en diversos campos como el urbanis- } \\
\text { mo, el transporte, la educación, el agro, etc. } \\
\text { - El crecimiento económico en el largo plazo producirá el desarrollo social, } \\
\text { por lo tanto sólo es necesario la focalización de los recursos a los más pobres } \\
\text { mientras ocurra esto. } \\
\text { - 1975-1982: fin de la industrialización, ventajas comparativas de recursos } \\
\text { naturales. }\end{array}$ \\
\hline 1984-2013 & $\begin{array}{l}\text { Modelo neoliberal ba- } \\
\text { sado en la exportación. }\end{array}$ & $\begin{array}{l}\text { - Apertura económica. } \\
\text { - Tratados de libre comercio. } \\
\text { - 1985-1990: industrialización a través de exportaciones de RRNN. } \\
\text { - Centralización, disminución del desarrollo regional. } \\
\text { - } 1991 \text { Neoliberalismo y asistencialismo social: Alta tasa de depredación de } \\
\text { RRNN. } \\
\text { - Alta contaminación ambiental especialmente en centros urbanos y gran } \\
\text { desigualdad. }\end{array}$ \\
\hline
\end{tabular}

Fuente: Elaboración propia, 2013. 
(metálica) y la explotación forestal, manteniéndose al margen la actividad agrícola y generando un despoblamiento del campo, lo que se evidencia en el crecimiento de ciudades intermedias durante este periodo como Chillán.

Además, dentro de las políticas se destaca la de privatización y liberalización de los mercados urbanos del suelo, que consistió en generar un sector inmobiliario privado que asumió el rol de desarrollo urbano y "desarrollo" de las políticas de vivienda social ${ }^{27}$. Por tanto, el crecimiento urbano queda sujeto a los requerimientos de rentabilidad de los mercados de suelo. Producto de esta política de privatización y liberalización del mercado de suelo, se experimenta una movilidad social de la población de altos ingresos hacia sectores ubicados fuera del espacio urbano, surgiendo las llamadas parcelas de agrado, que en el caso de Chillán se ubican preferentemente en el área nororiente y oriente de la ciudad (camino Coihueco y camino Las Mariposas).

La adopción del modelo neoliberal implicó grandes transformaciones para el país, en la ciudades se experimenta una nueva redistribución espacial de la población hacia espacios de periferias urbanas ${ }^{28}$.

Resultado de este proceso, y en el marco de una fuerte presión demográfica, se ha generado un

27 Montes, 2000

28 Dascal, 1995.
TABLA N6: SUBDIVISIÓN PREDIAL EN LA COMUNA DE CHILLÁN, SEGÚN LA APLICACIÓN DE LA LEY DE

\section{PREDIOS RÚSTICOS}

\begin{tabular}{lc} 
Chillán & $N^{\circ}$ subdivisiones entre 0,5 y 1 ha \\
\hline 2012 & 502 \\
\hline 2011 & 573 \\
\hline 2010 & 287 \\
\hline 2009 & 219 \\
\hline 2008 & 405 \\
\hline 2007 & 634 \\
\hline 2006 & 960 \\
\hline 2005 & 673 \\
\hline 2004 & 1.223 \\
\hline 2003 & 673 \\
\hline 2002 & 857 \\
\hline 2001 & 978 \\
\hline total & 7.984 \\
\hline
\end{tabular}

Fuente: SAG, 2012

proceso de especulación en el mercado de tierras que favorece el crecimiento de las superficies urbanizadas. Por tal motivo, la periferia se integra al crecimiento residencial urbano a través de la promulgación de la Ley de Predios Rústicos y de la normativa relacionada al cambio de uso del sue$l^{29}$, en su artículo 55 D. S. N ${ }^{\circ} 458$ del MINVU y D. L. N³.516 sobre división de predios rústicos que

29 Márquez, 1999. 
permite dividir libremente los "predios rústicos" hasta $5.000 \mathrm{~m}^{2}$.

En el caso de la comuna de Chillán, según registros del Servicio Agrícola Ganadero (SAG), desde el año 2001 al 2012, se han tramitado un total de 7.984 subdivisiones de predios rústicos entre $0,5 \mathrm{y}$ 1 há, que en la mayoría de los casos corresponden a subdivisión para la construcción de "parcelas de agrado", a expensas de suelos de excelente actitud agrícola.

Esta Ley es utilizada como mecanismo para la generación de áreas residenciales de carácter urbano (parcelas de agrado), figurando legalmente como predios rústicos, "evadiendo" de esta manera las exigencias de Ley General de Urbanismo y Construcciones, lo que en definitiva contribuye a la expansión residencial de la ciudad.

\section{Factores físicos naturales en la evolución de la ciudad de Chillán}

El crecimiento de la ciudad de Chillán ha estado marcado por los desastres naturales, a consecuencia de grandes sismos e inundaciones, que llevaron a tomar la determinación de refundar la ciudad en tres oportunidades. Desde su época fundacional, la expansión de su trama urbana, ha estado condicionada a los cambios de sitios fundacionales, tal como se observa en el siguiente mapa.

En la tabla $\mathrm{N}^{\circ} 7$ se describen los principales acontecimientos que han marcado el devenir de Chillán. La primera fundación se efectúa en las cercanías del río Chillán, el 26 de junio de 1580, por el mariscal Martín Ruiz de Gamboa, siendo destruida en 1655 producto de un levantamiento indígena. Por tal razón se refundó en un sitio cercano emplazado en el sector denominado "El Bajo". En 1751 las inundaciones afectaron el poblado, por lo que en dicho año se determinó cambiar el sitio de la ciudad a un sector más seguro, trasladándose al lugar denominado Alto de la Horca, actual plaza de Armas de Chillán Viejo.

Luego de 84 años, en 1835, un terremoto destruyó el incipiente caserío, con lo cual las autoridades de la época decidieron definitivamente refundar la ciudad en la actual Plaza de Armas de Chillán.

En 1939 ocurrió el peor desastre que ha afectado a la ciudad, con más de un $75 \%$ de las viviendas destruidas, con miles de muertos, que marcó profundamente a la sociedad de Chillán. Asimismo, gatilló un proceso de reconstrucción marcado por la incorporación de elementos de la arquitectura moderna, y por la conformación de viviendas de emergencia, que hasta el día de hoy se observan en la calle Palermo y en otros puntos de la ciudad, como "vestigios" que representan un momento histórico difícil para los habitantes de Chillán. 


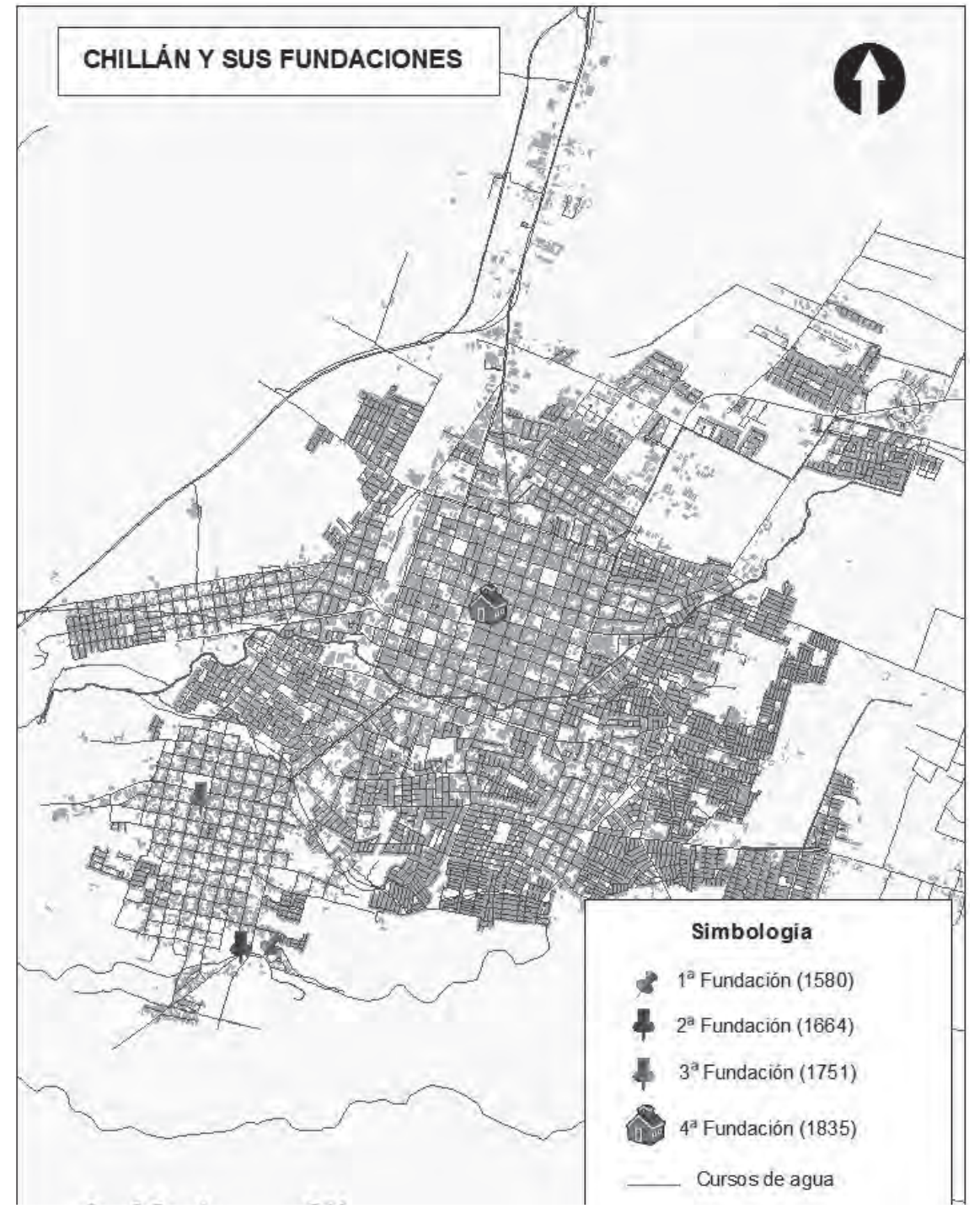

MAPA N³: AÑOS DE FUNDACIONES DE LA CIUDAD DE CHILLÁN

Fuente: Elaboración propia, sobre la base de Muñoz 1919.
178 revista invi № 82 / Noviembre 2014 / Volumen № 29: 157-187
ARTíCULO: Dinámica habitacional en Chillán, Chile (1906 - 2013) / Claudia Paola Espinoza Lizama 
TABLA N 7: FUNDACIONES Y DESASTRES EN LA CIUDAD DE CHILLÁN

\begin{tabular}{|c|c|}
\hline Fundación & Acontecimiento \\
\hline $1^{\text {a }}$ Fundación: 1580, en el lecho menor del río Chillán. & Destruida en 1655 por un levantamiento indígena. \\
\hline 2ª Fundación: 1664 en el sector el Bajo. & $\begin{array}{l}\text { Destruida por el terremoto de } 1751 \text { e inundada por el } \\
\text { desborde del Río Chillán. }\end{array}$ \\
\hline $\begin{array}{l}3^{\text {a }} \text { Fundación: } 1751 \text { en el Alto de la Horca, actual Plaza de } \\
\text { Armas de Chillán Viejo. }\end{array}$ & Destruida por el terremoto de 1835. \\
\hline \multirow{2}{*}{ 4ª Fundación: 1835, actual Plaza de Armas. } & $\begin{array}{l}\text { Azotada por el terremoto de 1939, cambia su morfología } \\
\text { urbana. }\end{array}$ \\
\hline & $\begin{array}{l}\text { Azotada por el terremoto de } 2010, \text { genera aumenta de } \\
\text { crecimiento hacia su periferia. }\end{array}$ \\
\hline
\end{tabular}

Fuente: Elaboración propia, 2014.

\section{TABLA N8: VARIACIÓN INTERCENSAL DEL DEPARTAMENTO DE CHILLÁN}

\begin{tabular}{|c|c|c|c|c|c|}
\hline Año & $\begin{array}{l}\mathrm{N}^{\circ} \text { de Habts. } \\
\text { del país }\end{array}$ & $\begin{array}{l}\text { Variación } \\
\text { intercensal país (\%) }\end{array}$ & $\begin{array}{l}\text { Departamento de } \\
\text { Chillán } N^{\circ} \text { Habts. }\end{array}$ & $\begin{array}{l}\text { Variación intercensal } \\
\text { comuna }(\%)\end{array}$ & Observaciones \\
\hline 1835 & 1.010 .332 & & & & \\
\hline 1843 & 1.083 .801 & 7,27 & & & \\
\hline 1854 & 1.439 .223 & 32,79 & 38.428 & & Provincia de Ñuble (1848) \\
\hline 1865 & 1.819 .223 & 26,40 & 48.281 & 25,64 & \\
\hline 1875 & 2.075 .071 & 14,06 & 55.425 & 14,80 & \\
\hline 1885 & 2.527 .320 & 21,79 & 60.767 & 9,64 & \\
\hline 1895 & 2.712 .145 & 7,31 & 67.089 & 10,40 & \\
\hline 1907 & 3.249 .279 & 19,80 & 71.246 & 6,20 & \\
\hline 1920 & 3.731 .573 & 14,84 & 72.771 & 2,14 & \\
\hline 1930 & 4.287 .445 & 14,90 & 81.230 & 11,62 & Provincia de Ñuble (1927) \\
\hline 1940 & 5.023 .539 & 17,17 & 86.158 & 6,07 & \\
\hline 1952 & 5.932 .995 & 18,10 & 92.320 & 7,15 & \\
\hline 1960 & 7.374 .115 & 24,29 & 109.469 & 18,58 & \\
\hline 1970 & 8.884 .768 & 20,49 & 128.903 & 17,75 & \\
\hline 1982 & 11.329 .736 & 27,52 & 382.052 & 196,39 & Provincia de Ñuble (1974) \\
\hline 1992 & 13.348 .401 & 17,82 & 419.249 & 9,74 & \\
\hline 2002 & 15.116 .435 & 13,25 & 447.824 & 6,82 & \\
\hline 2012 & 16.572 .475 & 9,63 & 461.547 & 3,06 & \\
\hline
\end{tabular}

Fuente: Elaboración propia sobre la base de Chile 1907, 1920, 1930, 1940, 1952, 1960, 1970, 1982, 1992, $2002,2012$. 
TABLA N9: CANTIDAD DE HABITANTES POR AÑO CENSAL DE LA PROVINCIA DEL ÑUBLE

\begin{tabular}{|c|c|c|c|c|c|c|c|c|c|c|c|}
\hline na & $\begin{array}{l}\text { Año } \\
1907\end{array}$ & 1920 & 1930 & 1940 & 1952 & 1960 & 1970 & 1982 & 1992 & 2002 & 2012 \\
\hline Bulnes & 11.331 & 12.338 & 12.887 & 13.154 & 13.416 & 15.112 & 16.295 & 18.612 & 19.638 & 20.567 & 20.693 \\
\hline Chillán & 9.117 & 38.688 & 56.974 & 61.535 & 67.896 & 82.868 & 102.907 & 136.496 & 166.225 & 161.961 & 175.405 \\
\hline Chillán Viejo & 857 & 10.299 & --- & --- & --- & --- & --- & --- & $-\cdots$ & 21.829 & 28.775 \\
\hline Cobquecura & 8.737 & 8.289 & 7.560 & 5.670 & 6.019 & 6.312 & 6.223 & 6.079 & 6.285 & 5.579 & 5.027 \\
\hline Coelemu & 7.637 & 8.152 & 11.941 & 13.723 & 10.489 & 11.945 & 12.580 & 15.638 & 16.602 & 16.024 & 15.662 \\
\hline Coihueco & 658 & 10.267 & 16.686 & 16.775 & 16.437 & 17.630 & 17.278 & 22.338 & 22.586 & 23.552 & 25.147 \\
\hline El Carmen & 10.867 & 9.663 & 9.790 & 11.080 & 11.810 & 13.025 & 13.194 & 14.076 & 14.071 & 12.780 & 12.274 \\
\hline Ninhue & 6.590 & 7.044 & 6.420 & 6.813 & 6.318 & 6.885 & 6.374 & 7.032 & 6.390 & 5.737 & 5.270 \\
\hline Ñiquén & .981 & 12.853 & 11.955 & 13.092 & 13.863 & 14.500 & 13.745 & 12.395 & 12.923 & 11.417 & 10.822 \\
\hline Pemuco & 6.814 & 8.103 & 6.589 & 7.081 & 6.541 & 7.303 & 7.594 & 8.187 & 8.494 & 8.788 & 8.342 \\
\hline Pinto & 8.148 & 7.858 & 7.570 & 7.848 & 7.937 & 9.023 & 8.718 & 9.235 & 8.874 & 9.767 & 10.659 \\
\hline Portezuelo & 9.971 & 10.204 & 10.518 & 10.612 & 9.613 & 11.249 & 10.769 & 7.172 & 5.904 & 5.362 & 4.970 \\
\hline Quillón & 8.618 & 17.070 & 9.418 & 9.562 & 9.524 & 12.453 & 13.434 & 15.026 & 14.361 & 15.023 & 16.392 \\
\hline Quirihue & .095 & 10.324 & 1.613 & 10.837 & 10.771 & 10.348 & 11.292 & 10.936 & 11.101 & 11.388 & 12.749 \\
\hline Ránquil & 5.513 & 4.887 & --- & $-\cdots$ & 5.906 & 6.513 & 6.815 & 7.403 & 6.162 & 5.657 & 5.969 \\
\hline San Carlos & .943 & 19.909 & 20.903 & 22.282 & 23.807 & 27.796 & 31.393 & 43.736 & 48.221 & 50.012 & 51.247 \\
\hline San Fabián & 7.371 & 6.326 & 6.318 & 6.463 & 6.285 & 7.295 & 7.676 & 3.862 & 3.752 & 3.522 & 3.809 \\
\hline San Ignacio & 10.820 & 10.168 & 10.699 & 12.112 & 12.460 & 13.270 & 13.542 & 15.003 & 16.395 & 16.084 & 15.549 \\
\hline San Nicolás & 7.487 & 7.949 & 8.038 & 8.399 & 8.693 & 9.489 & 9.161 & 8.005 & 9.332 & 9.596 & 10.628 \\
\hline Trehuaco & --- & --- & --- & --- & --- & --- & --- & 5.960 & 5.663 & 5.120 & 5.217 \\
\hline Yungay & 8.385 & 8.516 & 9.352 & 10.280 & 9.054 & 9.983 & 10.675 & 14.891 & 15.172 & 16.674 & 16.941 \\
\hline
\end{tabular}

Fuente: Elaboración propia sobre la base de Chile 1907, 1920, 1930, 1940, 1952, 1960, 1970, 1982, 1992, $2002,2012$. 
TABLA N 10: VARIACIÓN INTERCENSAL Y POBLACIÓN EN LAS COMUNAS DE CHILLÁN Y CHILLÁN VIEJO

\begin{tabular}{lcccccc} 
Comunas & $\begin{array}{l}\text { Año } 1907 \\
\mathrm{~N}^{\circ} \text { de habs. }\end{array}$ & $\begin{array}{l}\text { Año } 2012 \mathrm{~N}^{\circ} \text { de } \\
\text { habs. }\end{array}$ & $\begin{array}{l}\text { Variación } \\
\text { intercensal }\end{array}$ & $\begin{array}{l}\text { Año } 2002 \mathrm{~N}^{\circ} \text { de } \\
\text { habs. }\end{array}$ & $\begin{array}{l}\text { Año } 2012 \mathrm{~N}^{\circ} \text { de } \\
\text { habs. }\end{array}$ & $\begin{array}{l}\text { Variación } \\
\text { intercensal }\end{array}$ \\
\hline Chillán & 29.117 & 175.405 & 502,41 & 161.961 & 175.405 & 8,30 \\
\hline Chillán Viejo & 13.857 & 28.775 & 107,66 & 21.829 & 28.775 & 31,82 \\
\hline Total & & & & 183.790 & 204.180 & 11,09 \\
\hline
\end{tabular}

Fuente: Elaboración propia sobre la base de Chile 1907, 1920, 1930, 1940, 1952, 1960, 1970, 1982, 1992, $2002,2012$.

\section{Factor demográfico en la dinámica habitacional de Chillán}

La ciudad de Chillán, durante su historia siempre ha tenido un rol relevante en términos políticos -administrativos. En 1927 pasa a formar parte de la Provincia de Núble. En el año 1974, cuando se impulsó el actual proceso de regionalización, Chillán entonces queda inserto en la Región del Bío Bío, y adquiere la jerarquía de cabecera de la Provincia del Nuble.

Debido a su importancia, la ciudad concentró edificios públicos y delegaciones de servicios gubernamentales, con una función claramente administrativa, que derivó en un centro urbano dinámico, con comercio y servicios, que se consolidó con el paso de los años en una centralidad que ejerce una influencia y atracción, más allá de los límites provinciales.

En la tabla 9, se aprecia la evolución demográfica de la Provincia del Ñuble, observándose un aumento sostenido de la población. Cabe señalar que con la creación de la Provincia el año 1974, se agregan las comunas de Coelemu, Ránquil, Yungay y Trehuaco, a la nueva administración, por lo cual el censo del año 1982 registró una cantidad significativamente mayor de habitantes.

Así la Provincia del Nuble queda integrada por 21 comunas, consolidándose Chillán política y administrativamente. El factor político-administrativo entonces radica en que al sumarse nuevas comunas los habitantes y las autoridades políticas de los nuevos territorios anexados, necesariamente deben realizar trámites y gestiones en la capital provincial, incentivándose así nuevos movimientos migratorios. 
En consecuencia, el aumento demográfico de Chillán no solo se explica por el crecimiento vegetativo, sino que también por movimientos migratorios campo-ciudad, incentivados por las mejores expectativas de calidad de vida que ofrece Chillán, en su rol de centro administrativo, comercial, de servicios y generador de empleos.

Respecto de la evolución demográfica de cada una de las comunas de la provincia, se observa una tendencia a la concentración de la población en Chillán, en desmedro de las comunas rurales, creciendo a un ritmo mayor en relación con el resto de los territorios. Comunas rurales como Cobquecura, Niquén, Ninhue y San Fabián registran un constante decrecimiento poblacional.

Con el objetivo de demostrar el significativo crecimiento de la ciudad de Chillán, se utilizan los resultados censales de las comunas que la componen, Chillán y Chillán Viejo, dado que se desconocen antecedentes fidedignos respecto del número de habitantes que residían en la ciudad a principios del siglo XX.

El censo de población de 1907 registró un total de 29.117 habitantes en la comuna de Chillán y 13.857 en Chillán Viejo, mientras que en el año 2012 el censo contabilizó 175.405 y 28.775 habitantes, respectivamente. En términos porcentuales, la variación en un poco más de 100 años, en el número de habitantes de la comuna de Chillán, es
TABLA N¹1: EVOLUCIÓN DE LA DENSIDAD DE POBLACIÓN EN HAB/KM² DE LA PROVINCIA DE ÑUBLE

\begin{tabular}{lrrr} 
Comunas & Año & & \\
& 1992 & 2002 & 2012 \\
Bulnes & 46,16 & 48,35 & 48,64 \\
\hline Chillán & 290,98 & 316,95 & 343,26 \\
\hline Chillán Viejo & 55,86 & 74,76 & 98,54 \\
\hline Cobquecura & 11,03 & 9,79 & 8,82 \\
\hline Coelemu & 48,5 & 46,81 & 45,76 \\
\hline Coihueco & 12,71 & 13,25 & 14,15 \\
\hline El Carmen & 21,19 & 19,25 & 18,48 \\
\hline Ninhue & 15,94 & 14,31 & 13,14 \\
\hline Niquén & 26,11 & 23,06 & 21,86 \\
\hline Pemuco & 15,09 & 15,61 & 14,82 \\
\hline Pinto & 7,62 & 8,39 & 9,16 \\
\hline Portezuelo & 20,91 & 18,99 & 17,61 \\
\hline Quillón & 33,95 & 35,52 & 38,75 \\
\hline Quirihue & 18,85 & 19,33 & 21,65 \\
\hline Ránquil & 24,85 & 22,81 & 24,07 \\
\hline San Carlos & 55,17 & 57,22 & 58,64 \\
\hline San Fabián de Alico & 2,39 & 2,25 & 2,43 \\
\hline San Ignacio & 45,04 & 44,19 & 42,72 \\
\hline San Nicolás & 19,01 & 19,54 & 21,65 \\
\hline Trehuaco & 18,09 & 16,36 & 16,67 \\
\hline Yungay & 18,4 & 20,22 & 20,55 \\
\hline & & & \\
\hline
\end{tabular}

Fuente: INE, 2013. 
de alrededor de 500\%, mientras en Chillán Viejo alcanza el 107\%.

Comparando el último periodo intercensal, la variación porcentual en las comunas de Chillán y Chillán Viejo, representan un 8,3 y un 31,8\%. Claramente en el caso de la última comuna, el crecimiento está asociado a la ejecución de varios proyectos habitacionales en el sector nororiente, en el límite con la comuna de Chillán. Incluso fue necesario construir un nuevo Centro de Salud Familiar (CESFAM), para dar respuesta a la demanda de atención primaria de la población del sector.

La densidad de población, es un buen indicador para determinar el grado de concentración de los habitantes en un territorio. La comuna de Chillán es la que presenta el mayor valor de densidad y una tendencia al alza desde el año 1992 hasta la fecha. Cabe agregar que el crecimiento de la ciudad se ha desarrollado fundamentalmente de forma horizontal, a expensas de suelos de aptitud agrícola en áreas rururbanas de la zona oriente y nororiente de Chillán. El crecimiento vertical, por medio de la densificación predial y la construcción de edificación en altura no ha sido relevante, pese a que en los últimos años se está activando con la ejecución de al menos 5 proyectos de construcción de edificios (Avenidas O' Higgins, Diego de Almagro y Padre Hurtado).

\section{Conclusión}

La configuración urbana de la ciudad de Chillán, se puede explicar por distintos factores, entre ellos los desastres naturales, que marcaron en un comienzo el emplazamiento de la ciudad de Chillán en distintos sitios fundacionales, a consecuencia de terremotos e inundaciones que obligaron a refundar la ciudad en 4 sitios diferentes.

No obstante, el terremoto acaecido el año 1835 es el "responsable" de la configuración urbana actual de Chillán, debido a que significó el cambio de emplazamiento al sitio fundacional definitivo, en la actual Plaza de Armas y la conformación de un nuevo plano damero, a partir del cual se consolidó el Chillán "Nuevo", desarrollándose de forma paralela la zona urbana de Chillán Viejo. Sin embargo, el centro comercial, administrativo y de servicios, siempre ha estado alojado en el centro fundacional de Chillán.

Los modelos de desarrollo económico que ha adoptado Chile, marcaron el crecimiento de la ciudad de Chillán. En un primer momento, el modelo de sustitución de importaciones fortaleció el rol del Estado en el desarrollo económico, con un marcado énfasis en la industrialización, con la creación de la CORFO, lo que propició el crecimiento de Chillán, debido fundamentalmente a su posición estratégica en el valle central y cercano a la ciudad de Concepción. 
Posterior al año 1939, la ciudad de Chillán acelera su crecimiento poblacional, especialmente en la década de los 50', cuando se incentiva en el país el desarrollo regional, producto de la industrialización del país y la implementación del modelo de sustitución de importaciones.

El desarrollo económico que tuvo durante esos años Chillán, generó un crecimiento habitacional, dado que hay una relación directa entre actividades económicas desarrolladas, empleo, procesos migratorios, demanda de vivienda y crecimiento de las ciudades.

El éxodo rural que se produce durante la década de los años 50' y 60', origina la aparición de las primeras poblaciones emblemáticas tales como: Rosita O'Higgins, Marta Brunet y 20 de Agosto. Posteriormente el crecimiento residencial de Chillán es marcado por las tomas de terreno, acaecidas entre los años 1960 y 1972, y la posterior aplicación de programas habitacionales de operación sitio y la erradicación de campamentos, que aún persistían tras el terremoto de 1939 (políticas de viviendas habitacionales).

La apertura de la economía chilena, el año 1974, generó una activación de la actividad exportadora del país. Se fortalecieron, sin embargo, la exportación de comodities, en donde el rubro forestal fue la principal rama económica beneficiada. Esto trajo como consecuencia, la ocupación de amplias áreas rurales, en suelos con aptitud forestal, que fue subsidiada por el Estado chileno, mediante el DFL 701, gatillando proceso de migración campo - ciudad, principalmente hacia los centros urbanos de la región, tales como Chillán, Los Ángeles y Concepción.

El paradigma neoliberal, trascendió todos los ámbitos del quehacer nacional, tal es así, que el año 1979 se dictó y promulgó la Política Nacional de Desarrollo Urbano, que contribuyó a masificar la entrega de viviendas sociales, cediendo el Estado de Chile su rol principal a la empresa privada en la construcción de conjunto habitacionales, restándose y asumiendo solo a un rol subsidiario (entrega de subsidios y ahorro de las familias).

La apertura del mercado de suelos desvincula al estado de las políticas habitacionales e incentiva el crecimiento de los proyectos habitacionales. Luego de la vuelta a la democracia se acelera el crecimiento mediante la construcción de viviendas sociales hasta comienzos del siglo XXI, situación complementada por la aparición de proyectos habitacionales de inmobiliarias, que construyen conjuntos de viviendas para clases sociales medias y altas.

Posteriormente se dicta la Ley de Predios Rústicos $\mathrm{N}^{\circ}$ 3.516, que establece la subdivisión predial de los suelos rurales en un mínimo de $5.000 \mathrm{~m}^{2}$, generando una proliferación de parcelas de agrado en la zona periférica de Chillán, de forma difusa y segregando la ciudad. 
Finalmente, la ciudad de Chillán, desde principios del siglo XX hasta la actualidad, ha experimentado un fuerte crecimiento horizontal. El año 1900 la "mancha urbana" ocupaba 379 há, mientras el año 2013 se extiende sobre una superficie total de 2.624 há. Es decir, en 113 años de historia, Chillán experimentó un crecimiento físico de 2.245 hectáreas.

\section{Bibliografía}

ABARZA ORTEGA, César; ARRIAGADA ARRIAGADA, Víctor y LÓPEZ MEDINA, Claudia. El proceso de periurbanización asociado a la ciudad de Chillán, factores condicionantes e implicancias socioespaciales y ambientales. Concepción, Universidad del Bío Bío, Chile. 2001. Tesis para optar al Título de Profesor de Educación Media en Historia y Geografía.

ANABALÓN PINTO, Nelson. Chillán una ciudad morfológica y socialmente fragmentada en busca del desarrollo sustentable. Urbano. 9(13): 92-94, 2006. ISSN 0717-3997.

AZÓCAR, Gerardo; SANHUEZA, Rodrigo y HENRíQUEZ, Cristián. Cambio en los patrones de crecimiento en una ciudad intermedia: el caso de Chillán en Chile Central. [En línea]. EURE Revista de Estudios Urbano Regionales. 29(87): 79-92, 2003. ISSN 0250-7161. Disponible en: http://dx.doi. org/10.4067/S0250-71612003008700006
BORGEL, Reinaldo. Geografía de Chile: geomorfología. Santiago, Instituto Geográfico Militar. 1982. Colección Geografía de Chile, v. II.

BRAIN, Isabel; CUBILLOS, Gonzalo y SABATINI, Francisco. Integración social urbana en la nueva política habitacional. Santiago, Pontificia Universidad Católica de Chile, Vicerrectoría de Comunicaciones y Asuntos Públicos, 2007. Temas de la agenda pública, año $2 \mathrm{~N}^{\circ} 7$.

CASTILLO MORALES, Francis B.; DURÁN ARRIAGADA, Silvia J.; REYES OÑATE, José E.; RUBILAR HENRÍQUEZ, Luis E. y SEPÚLVEDA RAMÍREZ, César E. Diagnóstico socioeconómico en la ciudad de Chillán. Chillán, Chile, Universidad del Bío Bío. 1986. Tesis para optar al Título de Profesor de Educación Media en Historia y Geografía.

CHILE. Comisión Central de Censo. Censo general de la población de Chile. 1907.

CHILE. Dirección de Estadísticas y Censos. XIII Censo de población y II de Vivienda de la República de Chile 1960.Chile. 1960. Chile. 1960.

CHILE. Dirección General de Estadística. IX Censo de población de la República de Chile 1920. 1925.

_ X Censo de población de la República de Chile. 1930.

_ XI Censo de población de la República de Chile 1920. CELADE. 1940.

CHILE. INE Instituto Nacional de Estadísticas de Chile. Estadísticas de Chile en el siglo XX. Santiago de Chile, La Nación, 114 p. 1999.

revista invi No 82 / Noviembre 2014 / Volumen Nº 29: 157-187 
_ Resultados preliminares del censo de población y vivienda. Chile. 2012.

—_ XIV Censo de población. Chile. 1970.

__ XV Censo de población y IV de vivienda. Chile. 1982.

_ XVI Censo de población y V de vivienda. Chile. 1992.

_ XVII Censo de población y VI de vivienda. Chile. 2002.

CHILE. Servicio Nacional de Estadísticas y Censos. XII Censo general de población y I de vivienda 1952. Chile. 1952.

DASCAL, G; VILLAGRÁN, J. La periurbanización y la agricultura de Santiago. Revista de geografía Norte Grande. (22): 35-39, 1995. ISSN 0718-3402

DUCCI, María Elena La política habitacional como instrumento de desintegración social. Efectos de una política de vivienda exitosa. En: CASTILLO, María José, comp. e HIDALGO, Rodrigo, comp. Cien años de vivienda social en Chile. Santiago, Ediciones UNAB. 2007. p. 107-123.

DUCCI, M. Mirar. México, Sastrel. 1998.

DUCCI, María Elena. Chile: el lado oscuro de una política de vivienda exitosa. [En línea]. EURE Revista de Estudios Urbano Regionales. 23(69): 99-115, 1997. ISSN 0250-7161. Disponible en: http://eure. cl/index.php/eure/article/view/1164

HENRíQUEZ, Cristián y AZÓCAR, Gerardo. Propuesta de modelos predictivos en la planificación territorial y evaluación de impacto ambiental. [En línea]. Scripta Nova. Revista Electrónica de Geografía y Ciencias Sociales. 11(245, 41), 2007. ISSN 1138-9788. Disponible en: http://www.ub.edu/ geocrit/sn/sn-24541.htm

HENRíQUEZ, Marta. Dinámica histórica de la estructura en las ciudades intermedias de Chillán y Chillán Viejo. En: HENRÍQUEZ, Marta. La sustentabilidad socio-ambiental de las ciudades intermedias de Chillán y Chillán Viejo. Universidad de Concepción, Centro de Formación e Investigación en Ciencias Ambientales EULA. 2006. Tesis para optar al grado de Doctor en Ciencias Ambientales.

HIDALG0, Rodrigo. Vivienda social y espacios urbanos en Santiago de Chile. Una mirada retrospectiva a la acción del Estado y las primeras décadas del siglo XX. [En línea]. EURE Revista de Estudios Urbano Regionales. 27(83): 83-106, 2002. ISSN 11389788. Disponible en: http://dx.doi.org/10.4067/ S0250-71612002008300006

MÁRQUEZ, Marco. Ordenamiento territorial de los espacios rurales en Chile. Revista Norte Grande. (26): 113-118, 1999. ISSN 0718-3402

MIRANDA, Rodrigo. La frustrada reconstrucción de Chillán por Le Corbusier. [En línea]. La Tercera. 6 marzo 2010. Disponible en: http://www.latercera. com/contenido/1453_231549_9.shtml

MONTES, Carlos. A 20 años de la liberalización de los mercados de suelo. [En línea]. EURE Revista de Estudios Urbano Regionales. 26(77): 137-141, 2000. 
ISSN 1138-9788. Disponible en: http://dx.doi. org/10.4067/S0250-71612000007700006

MUÑOZ OLAVE, Reinaldo. Historia de Chillán: sus fundaciones y destrucciones (1580-1835). Santiago de Chile, Imprenta de San José. 1919.

NIEMEYER, H. y CERECEDA, P. Geografía de Chile: hidrografia. Santiago de Chile, Instituto Geográfico Militar. 1984. Colección Geografía de Chile, v. VIII.

OLAVE FARÍAS, Didima. La vivienda, una variable e calidad de vida en la ciudad de Chillán-Chile. [En línea]. Tiempo y Espacio. 4(4): 95-112, 1994. ISSN 0716-9671. Disponible en: http://www.ubiobio. cl/miweb/webfile/media/222/Espacio/1994/6.pdf

PFLIEGER, Geraldine. Historia de la universalización del acceso al agua y al alcantarillado en SantiagoChile (1970-1995). [En línea].EURE Revista de Estudios Urbano Regionales. 34(103): 131-152, 2008. ISSN 1138-9788. Disponible en: http://dx.doi. org/10.4067/S0250-71612008000300007

REYES COCA, Marco Aurelio. Breve historia de Chillán 1835-1939. Chillán, Universidad de Concepción. 2000. Cuadernos del Bío-Bío, v 22.

SABATINI, Francisco y BRAIN, Isabel. La segregación, los guetos y la integración social urbana: mitos y claves. [En línea]. EURE Revista de Estudios Urbano Regionales. 34(103): 5-26, 2008. ISSN 11389788. Disponible en: http://dx.doi.org/10.4067/ S0250-71612008000300001
SEPÚlVEdA JARA, María Paz y ESPINOZA URRA, Cynthia Andrea. Expansión urbana de la ciudad de Chillán, región del Bío-Bío y sus consecuencias en el espacio urbano entre 1980-2011. Chillán, Chile, Universidad del BíoBío. 2011. Tesis para optar al Título de Profesor de Educación Media en Historia y Geografía. 